\title{
Structured, proactive care coordination versus usual care for Improving Morbidity during Post-Acute Care Transitions for Sepsis (IMPACTS): a pragmatic, randomized controlled trial
}

Marc Kowalkowski ${ }^{1 *}$ (D), Shih-Hsiung Chou ${ }^{1}$, Andrew McWilliams ${ }^{1,2}$, Cathryn Lashley ${ }^{3}$, Stephanie Murphy ${ }^{4}$, Whitney Rossman ${ }^{1}$, Alfred Papali, Alan Heffner ${ }^{6}$, Mark Russo ${ }^{7}$, Larry Burke ${ }^{8}$, Michael Gibbs ${ }^{6}$, Stephanie P. Taylor ${ }^{2}$ and On behalf of Atrium Health ACORN Investigators

\begin{abstract}
s
Background: Hospital mortality for patients with sepsis has recently declined, but sepsis survivors still suffer from significant long-term mortality and morbidity. There are limited data that support effective strategies to address post-discharge management of patients hospitalized with sepsis.

Methods: The Improving Morbidity during Post-Acute Care Transitions for Sepsis (IMPACTS) study is a pragmatic, randomized controlled trial at three hospitals within a single healthcare delivery system comparing clinical outcomes between sepsis survivors who receive usual care versus care delivered through the Sepsis Transition and Recovery (STAR) program. The STAR program includes a centrally located nurse navigator using telephone counseling and electronic health record-based support to facilitate best-practice post-sepsis care strategies for patients during hospitalization and the 30 days after hospital discharge, including post-discharge review of medications, evaluation for new impairments or symptoms, monitoring existing comorbidities, and palliative care referral when appropriate. Adults admitted through the Emergency Department with suspected infection (i.e., antibiotics initiated, bacterial cultures drawn) and deemed, by previously developed risk-stratification models, high risk for readmission or death are included. Eligible patients are randomly allocated 1:1 to either Arm 1, usual care or Arm 2, STAR. Planned enrollment is 708 patients during a 6-month period. The primary outcome is the composite of all-cause hospital readmissions and mortality assessed 30 days post discharge. Secondary outcomes include 30- and 90-day hospital readmissions, mortality, emergency department visits, acute care-free days alive, and acute care and total costs.
\end{abstract}

Discussion: This pragmatic evaluation provides the most comprehensive assessment to date of a strategy to improve delivery of recommended post-sepsis care.

Trial registration: ClinicalTrials.gov, NCT03865602. Registered retrospectively on 6 March 2019.

Keywords: Sepsis, Infection, Continuity of patient care, Patient navigator, Health services, Pragmatic clinical trial

\footnotetext{
* Correspondence: Marc.Kowalkowski@AtriumHealth.org

${ }^{1}$ Center for Outcomes Research and Evaluation, Atrium Health, 1540 Garden

Terrace, Suite 308, Charlotte, NC 28203, USA

Full list of author information is available at the end of the article
}

(C) The Author(s). 2019 Open Access This article is distributed under the terms of the Creative Commons Attribution 4.0 International License (http://creativecommons.org/licenses/by/4.0/), which permits unrestricted use, distribution, and reproduction in any medium, provided you give appropriate credit to the original author(s) and the source, provide a link to the Creative Commons license, and indicate if changes were made. The Creative Commons Public Domain Dedication waiver (http://creativecommons.org/publicdomain/zero/1.0/) applies to the data made available in this article, unless otherwise stated. 


\section{Background}

Sepsis is a common, life-threatening condition defined by organ dysfunction due to a dysregulated response to infection [1]. Aggressive early sepsis identification and treatment initiatives have decreased hospital mortality for patients with sepsis [2-4]. As mortality rates have improved, there has been a growing recognition of the downstream effects of sepsis for the approximately 14 million annual sepsis survivors who encounter increased long-term mortality and morbidity across functional, cognitive, and psychological domains [4-10].

Currently, post-acute care resources are not adequate to address the needs of sepsis survivors [11-14]. Inadequate post-sepsis care strategies are reflected by the high rates of adverse outcomes after sepsis hospital discharge such as increased mortality risk and strikingly high rates of healthcare utilization, including a 90-day hospital readmission rate of $40 \%$ and over 3,000,000,000 USD in potentially preventable costs [15-19]. To address persistent morbidity and mortality for sepsis survivors, experts developed best-practice recommendations to guide delivery of post-sepsis care [20]. These recommendations are directed toward the specific challenges and sequelae following a sepsis hospitalization and include: identification and treatment of new physical, mental, and cognitive deficits; review and adjustment of medications; surveillance of treatable conditions that commonly lead to poor outcomes, including chronic conditions that may de-stabilize during sepsis and recovery; and focus on palliative care when appropriate. Implementation of these recommendations is hindered by a gap in understanding how to best integrate interventions into the complex and fragmented post-discharge setting (e.g., lack of provider time and patient engagement, limited access to care management, and insufficient institutional support) [21-26]. Furthermore, implementing these care recommendations requires health system investments, yet the effect of these investments on patient outcomes and costs has not been evaluated to date.

To evaluate the implementation and effectiveness of best-practice post-sepsis care recommendations, we developed a sepsis survivor transition program, in which a nurse facilitates implementation of recommended care practices and bridges care gaps through a program called Sepsis Transition and Recovery (STAR). The Improving Morbidity during Post-Acute Care Transitions for Sepsis (IMPACTS) trial is designed to test the hypothesis that implementation of the STAR program reduces 30-day readmission and mortality rates for high-risk patients with suspected sepsis compared to usual care alone.

\section{Methods}

\section{Design}

The IMPACTS study is a pragmatic, randomized controlled trial with two parallel groups being conducted at three tertiary care hospitals located within metro Charlotte, NC, USA to evaluate clinical outcomes for sepsis survivors receiving usual care versus care delivered through the STAR program following hospitalization. The STAR program is designed using the Chronic Care Model theoretical framework [27], which promotes care planning, active follow-up, and patient, provider, and community engagement, to increase adherence to best-practice recommendations and improve care coordination between hospital and post-acute care transitions during sepsis recovery. Consistent with a pragmatic study design, eligibility criteria are broad and study procedures are embedded into the context of routine care. This trial was approved by the Atrium Health (AH) Institutional Review Board (IRB) with a waiver of informed consent as this evaluation utilizes elements routinely collected in usual clinical practice and deemed to present minimal risk to study participants (IRB \#01-19-24E; protocol version 1.0, date December 17, 2018). The trial is registered with ClinicalTrials.gov (NCT03865602), and the trial protocol adheres to the Standardized Protocol Items: Recommendations for Interventional Trials (SPIRIT) guidelines [28] (for SPIRIT checklist and figure, see Additional files 1 and 2) and the Pragmatic-Explanatory Continuum Indicator Summary 2 (PRECIS-2) domains for the design of pragmatic studies (for diagram of PRECIS-2 domains, see Additional file 3) [29].

\section{Study setting and population}

This trial will occur at three facilities within $\mathrm{AH}$, one of the largest, integrated healthcare delivery systems in the United States. The study population is depicted in Fig. 1 and includes adults admitted to the hospital from the Emergency Department (ED) who meet the following inclusion criteria: $\geq 18$ years of age; oral or parenteral antibiotic or bacterial culture order within $24 \mathrm{~h}$ of ED presentation and either culture drawn first, antibiotics ordered within $48 \mathrm{~h}$ or antibiotics ordered first, culture ordered within $48 \mathrm{~h}$ (adapted from Third International Consensus Definitions for Sepsis and Septic Shock criteria) [30]; not discharged from the hospital at the time the daily list of eligible patients is generated each weekday morning; and deemed high risk for either 30-day readmission or mortality, defined as a readmission risk probability $\geq 20 \%$ or mortality risk probability $\geq 10 \%$.

Patients are excluded if they: receive antibiotics only as part of pre-operative prophylaxis; transfer from other acute care hospitals; have a code status documented as "do not resuscitate" or "do not intubate" within $24 \mathrm{~h}$ after admission (due to the general assumption of increased risk of exposure to less aggressive treatment); reside $>2.5 \mathrm{~h}$ drive time 


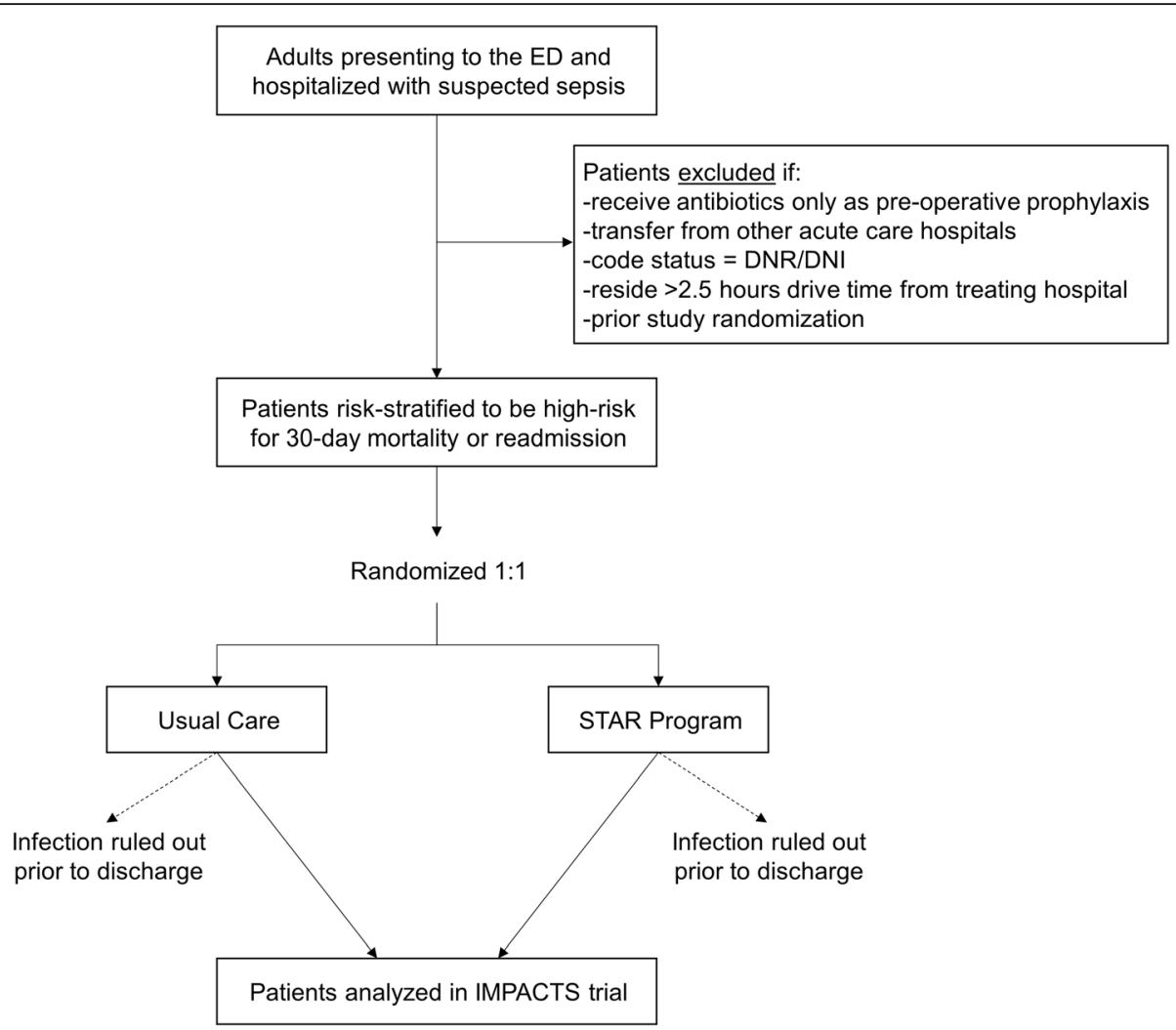

Fig. 1 Patient flow diagram for participation in THE IMPACTS trial. The study population includes adults presenting to the Emergency Department (ED) who meet the following inclusion criteria: $\geq 18$ years of age; oral or parenteral antibiotic or bacterial culture order within $24 \mathrm{~h}$ of ED presentation and either culture drawn first, antibiotics ordered within $48 \mathrm{~h}$ or antibiotics ordered first, culture ordered within $48 \mathrm{~h}$; not discharged from the hospital at the time the daily list of eligible patients is generated each weekday morning; and deemed high risk for either 30-day readmission or mortality using risk-scoring models applied daily to real-time clinical data on acute and chronic factors. Patients are excluded based on receipt of prophylactic antibiotics only, hospital transfers, "do not resuscitate" or "do not intubate" (DNR/DNI) code status, distance of residence from treating hospital, and prior study randomization. Patients who have infection ruled out prior to hospital discharge are also excluded. IMPACTS Improving Morbidity during Post-Acute Care Transitions for Sepsis, STAR Sepsis Transition and Recovery

from the treating hospital (due to the maximum reach of the community paramedicine services leveraged within the STAR program and the general assumption that these patients may have less comprehensive utilization tracking within $\mathrm{AH}$ record systems for study outcomes); or have been previously randomized as part of this study. Because we initially identify patients with suspected infection in order to intervene with high-risk patients in near real time, we will re-evaluate eligibility based on infection status at the time of hospital discharge. Specifically, patients who have had an infection diagnosis ruled out during their hospitalization will be excluded for the purposes of analysis (i.e., rule-out documented in medical record, assessed by blinded, adjudicated chart review for both arms). All remaining eligible patients at the time of discharge will be included in analyses.

\section{Risk scoring and recruitment}

Separate risk prediction scores are applied to assess 30-day hospital readmission and 30-day mortality using previously developed logistic regression models. Each model is derived from readily captured variables collected as part of routine clinical care during the first $24 \mathrm{~h}$ after ED presentation, such as physiologic measurements, laboratory values, basic sociodemographic characteristics, and personal medical history [31]. All model covariates are sourced from a patient's clinical data during hospitalization and billing history at the time of hospital admission for near real-time application. Model performance was determined using 10-fold crossvalidation (30-day mortality model discrimination: area under the receiver operator characteristic curve $(\mathrm{AUC})=$ 0.85 , negative predictive value $(\mathrm{NPV})=0.97 ; 30$-day readmission model discrimination: $\mathrm{AUC}=0.70, \mathrm{NPV}=0.89$ ). Highrisk features included older age, higher number of comorbidities (Charlson Comorbidity Index), hospital admission within the last 90 days, chemotherapy receipt within the last 90 days, respiratory agent receipt within the last 90 days, hyperlactatemia, hypotension, leukocytosis, and tachypnea. Risk probabilities between 0 and 1 are assigned to hospitalized patients for each outcome. 
Each weekday (i.e., Monday-Friday), we generate an automated list of eligible patients at high risk for 30-day mortality or readmission, as identified by our previously developed risk models. Patients are randomly assigned to STAR or usual care arms. For those patients allocated to receive care via STAR, their information is sent by secure e-mail to the STAR navigator. For patients in both arms, data from the automated, daily patient list are sent to the study database for tracking via a computer-based process. At any point, patients may decline participation in STAR or any components of usual care.

\section{Trial interventions}

Patients in the usual care group continue to receive usual care throughout their hospitalization and following discharge. Usual care elements are not prescribed but typically consist of: patient education and follow-up instructions at discharge; routine recommendations for follow-up visits with primary care providers; arrangements for home health services, transitional care, or care management follow-up based on each patient's needs but not specifically tailored to the sepsis population; and, when necessary, discharge to post-acute skilled nursing facility (SNF) or acute rehabilitation settings but with no sepsis-specific follow-up. Consistent with the concept of a pragmatic trial, aspects of usual care are determined by treating clinicians independent of trial assignment.

Patients in the intervention arm receive care via the STAR program. The STAR program employs a centrally located nurse navigator who has clinical knowledge of sepsis and its cognitive and functional sequelae, core competencies in navigating transitions of care (e.g., facilitating communication, coordinating care, assessing/addressing barriers to care, providing patient education and practical resource information/ referrals), and works as an extension of AH's Transition Services within the Division of Hospital Medicine, which is a multidisciplinary team providing acute care support during the peri-discharge interval. We have previously published on the potential for Transition Services to improve 30-day readmission rates in patients with sepsis [32, 33]; this study seeks to extend the reach of those services through nurse navigation. All outreach from the STAR navigator occurs virtually (e.g., telephone, messaging, and electronic health record (EHR) systems) to provide proactive coordination and monitoring for patients. The targeted, evidencebased or best-practice care components include: identification of and referral for new physical, mental, and cognitive deficits; review and recommendation for adjustment of medications; surveillance of treatable conditions that commonly lead to poor outcomes; and referral to palliative care when appropriate (Table 1).
At the initial telephone-based contact with the patient or caregiver during hospitalization, the STAR navigator introduces the STAR program and, in situations when the patient can participate, conducts a mental health screening using the Patient Health Questionnaire (PHQ)-2, with reflex administration of the PHQ-9 for positive PHQ-2 (i.e., $\geq 3$ points on a scale of 0-6 points) [34]. The STAR navigator communicates the results to the patient's attending physician. Additionally, the STAR navigator confirms consultations with physical therapy (with recommendation to consult delivered to the care team, if not in place), antibiotic stewardship (i.e., a coordinated program promoting appropriate antibiotic use with a pharmacist review of type and duration, with a review requested by the navigator if not completed), and an additional infectious disease specialist if ongoing systemic inflammatory response syndrome criteria are present more than $48 \mathrm{~h}$ after infection onset (i.e., at least two of the following clinical findings: body temperature $<36^{\circ} \mathrm{C}$ or $>38^{\circ} \mathrm{C}$, heart rate $>90$ beats/min, respiratory rate $>20$ breaths/ min, and white blood cell count $<4000 / \mathrm{mm}^{3}$ or $>12$, $000 / \mathrm{mm}^{3}$ ) [35, 36]. Finally, if the patient has a serious, chronic illness and either failure to improve after 5 days or a previous hospital admission in the last 60 days, the STAR navigator recommends a goals of care discussion led by the care team or a palliative care consultation [37]. Every 24-48 h during the remainder of the hospital stay, the STAR navigator reviews the patient's electronic record, communicates with the patient or caregiver, and checks with the clinical case management team for updated discharge planning. Prior to discharge, the STAR navigator provides infection-specific education to the patient and caregiver, which also includes what to expect during transition from the hospital and written information on scheduled outpatient appointments and planned telephone touchpoints. The STAR navigator also reviews discharge orders and confirms inpatient pharmacist review of high-risk medications, including: appropriate indication if prescribed proton pump inhibitor, opioids, benzodiazapines, or antipsychotics; appropriate medications prescribed for chronic lung disease or chronic heart failure (e.g., inhaled corticosteroids for chronic lung disease; or diuretics, beta blockers, angiotensin-converting enzyme inhibitors, aspirin, or statins for chronic heart failure); and medication doses adjusted as needed if any new or worsening renal failure.

After discharge, the STAR navigator follows patients regardless of the discharge location (e.g., home, SNF) and remotely monitors via EHR-based and telephone-based review throughout the 30 days post hospital discharge (Fig. 2). Specifically, the STAR navigator provides telehealth monitoring at $<48 \mathrm{~h}, 72-96 \mathrm{~h}$, and 7-10 days post 
Table 1 Post-sepsis guidelines with the Sepsis Transition and Recovery (STAR) program task

\begin{tabular}{|c|c|c|}
\hline Core component/evidence & Recommendation $^{a}$ & STAR task \\
\hline \multicolumn{3}{|c|}{ Screen for new physical, mental, and cognitive deficits after sepsis } \\
\hline $\begin{array}{l}\text { Functional disability: patients aged } \geq 65 \text { years develop } \\
\text { one or two new functional limitations }\end{array}$ & $\begin{array}{l}\text { - Prescribe structured exercise program } \\
\text { - Referral to physical/cardiac/pulmonary } \\
\text { rehabilitation as needed }\end{array}$ & $\begin{array}{l}\text { Confirm functional assessment } \\
\text { (physical therapy). Refer as } \\
\text { needed }\end{array}$ \\
\hline $\begin{array}{l}\text { Swallowing impairment: of patients aged } \geq 65 \text { years, } \\
1.8 \% \text { readmitted }<90 \text { days for aspiration pneumonitis }\end{array}$ & $\begin{array}{l}\text { - Screen for cough, dysphagia, weak voice } \\
\text { - Referral to speech therapy as needed }\end{array}$ & $\begin{array}{l}\text { Confirm screen and team aware. } \\
\text { Refer as needed }\end{array}$ \\
\hline $\begin{array}{l}\text { Mental health impairment: prevalence for clinically } \\
\text { significant anxiety 32\%, depression 29\%, and PTSD 44\% }\end{array}$ & $\begin{array}{l}\text { - Review details of hospital course (e.g., ICU diary) } \\
\text { - Depression screen } \\
\text { - Referral to peer support or behavioral health as } \\
\text { needed }\end{array}$ & $\begin{array}{l}\text { Mental health screen. Refer as } \\
\text { needed }\end{array}$ \\
\hline \multicolumn{3}{|l|}{ Review and adjust long-term medications } \\
\hline $\begin{array}{l}\text { Medication errors: errors of omission and commission } \\
\text { occur in up to } 25 \% \text { of patients, depending on the } \\
\text { medication }\end{array}$ & $\begin{array}{l}\text { - Review antibiotic choice, dose, duration } \\
\text { - Start/continue medications for comorbidities; } \\
\text { adjust for BMl, etc. } \\
\text { - Discontinue hospital medications without } \\
\text { ongoing indication }\end{array}$ & $\begin{array}{l}\text { Antibiotic stewardship } \\
\text { Medication reconciliation Vitals/ } \\
\text { weight }\end{array}$ \\
\hline \multicolumn{2}{|c|}{ Anticipate and mitigate risk for common and preventable causes of health deterioration } & $\begin{array}{l}\text { Routine virtual follow-up Sched- } \\
\text { ule provider visits }\end{array}$ \\
\hline $\begin{array}{l}\text { Infection: of patients aged } \geq 65 \text { years, } 11.9 \% \text { readmitted } \\
<90 \text { days for infection ( } 6.4 \% \text { for sepsis) }\end{array}$ & $\begin{array}{l}\text { - Patient education about symptoms of sepsis, } \\
\text { recurrence } \\
\text { - Appropriate vaccination } \\
\text { - Monitor for symptomatic improvement in index } \\
\text { infection }\end{array}$ & $\begin{array}{l}\text { Education } \\
\text { Medication reconciliation } \\
\text { Monitor symptoms }\end{array}$ \\
\hline $\begin{array}{l}\text { Heart failure exacerbation: of patients aged } \geq 65 \text { years, } \\
5.5 \% \text { readmitted }<90 \text { days for CHF }\end{array}$ & $\begin{array}{l}\text { - Reassess beta blocker, diuretic, ACE-inhibitor } \\
\text { dosing } \\
\text { - Monitor volume status (fluid balance), recognizing } \\
\text { dry weight may be decreased if muscle mass is } \\
\text { lost }\end{array}$ & $\begin{array}{l}\text { Medication reconciliation Vitals/ } \\
\text { weight } \\
\text { Monitor symptoms }\end{array}$ \\
\hline $\begin{array}{l}\text { Acute renal failure: of patients aged } \geq 65 \text { years, } 3.3 \% \\
\text { readmitted }<90 \text { days for acute renal failure }\end{array}$ & $\begin{array}{l}\text { - Monitor renal function; laboratory testing as } \\
\text { needed } \\
\text { - Reassess need and dosages for renally cleared, } \\
\text { nephrotoxic agents }\end{array}$ & $\begin{array}{l}\text { Monitor symptoms } \\
\text { Confirm CBC/BMP } \\
\text { Medication reconciliation }\end{array}$ \\
\hline $\begin{array}{l}\text { COPD exacerbation: of patients aged } \geq 65 \text { years, } 1.9 \% \\
\text { readmitted }<90 \text { days for COPD exacerbation }\end{array}$ & $\begin{array}{l}\text { - Confirm/initiate appropriate controller inhalers } \\
\text { - Appropriate vaccination } \\
\text { - Review use of benzodiazepines/opioids }\end{array}$ & $\begin{array}{l}\text { Monitor symptoms } \\
\text { Medication reconciliation }\end{array}$ \\
\hline Assess appropriateness for palliative care & $\begin{array}{l}\text { - Palliative care screen/consult as indicated } \\
\text { - Goals of care; educate on disease progression/ } \\
\text { terminal }\end{array}$ & $\begin{array}{l}\text { Discuss palliative care consult } \\
\text { Goals of care }\end{array}$ \\
\hline
\end{tabular}

$A C E$ angiotensin converting enzyme, $B M I$ body mass index, $B M P$ basic metabolic panel, $C B C$ complete blood count, $C H F$ chronic heart failure, $C O P D$ chronic obstructive pulmonary disease, ICU intensive care unit, PTSD, post-traumatic stress disorder

${ }^{\mathrm{a}}$ Recommendations from Prescott and Angus [20]

discharge. Within 24-48 h of hospital discharge, the STAR navigator contacts the patient or caregiver for initial postdischarge medication reconciliation, with a review by the AH Transition Services pharmacist and confirmation that the patient has filled or received all medications needed. The STAR navigator coordinates with the patient's primary care provider or AH Transition Services to address any outstanding medication needs. Also at this touchpoint, the STAR navigator monitors for fever $\left(>38^{\circ} \mathrm{C}\right.$ after recheck), new or worsening symptoms (e.g., dyspnea, diarrhea, or redness, swelling, or pain (for skin and soft tissue infection)), and new limitations in functional status (e.g., not out of bed, not eating). Concerns identified through proactive monitoring prompt a primary care provider contact for follow-up within $24 \mathrm{~h}$. If the primary care provider cannot be reached after one attempt, the navigator contacts $\mathrm{AH}$ Transition Services to coordinate either a virtual visit with a physician facilitated by community paramedicine or an inperson physician visit [32]. The STAR navigator also meets at least weekly with the AH Transition Services Medical Director to review ongoing cases and coordinate additional support as needed. Additional touchpoints at $72-96 \mathrm{~h}$ and 7-10 days post discharge include similar elements (i.e., medication reconciliation, targeted symptom monitoring, vitals and weight checks, confirmation that the patient can make scheduled outpatient appointments) and response (i.e., coordinating follow-up with primary care or AH Transition Services within $24 \mathrm{~h}$ for concerning issues). If a provider visit has been completed, the STAR navigator reviews any visit notes, available laboratory values (e.g., complete 


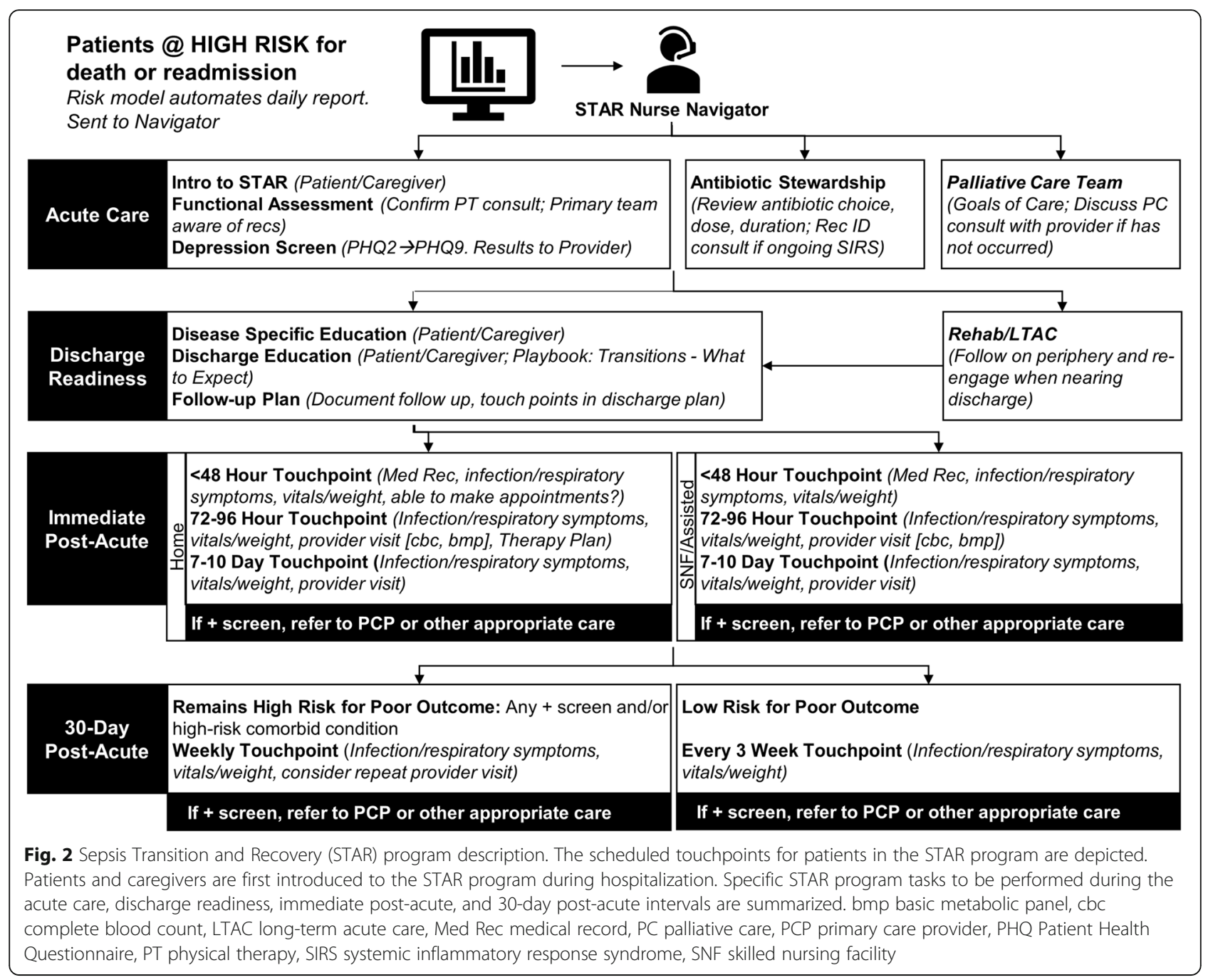

blood count, basic metabolic panel), and documented therapy plan. After the first 10 days following hospital discharge, the STAR navigator maintains weekly telehealth touchpoints with patients who remain at high risk for poor outcome, defined as any previous positive screen or highrisk comorbid condition (e.g., chronic lung disease, heart failure) [10, 38-40]; and one additional third-week touchpoint with patients considered low risk after the first 10 days post discharge. Each of these post-acute touchpoints include targeted symptom monitoring, vitals and weight check, and escalation to an additional outpatient provider visit within $24 \mathrm{~h}$ if there are concerns. Any identified concerns again prompt an attempt to contact the primary care provider followed by AH Transition Services. The STAR program intervention completes 30 days post hospital discharge.

\section{Treatment allocation}

Eligible patients are randomly allocated $1: 1$ to receive usual care or the STAR program using a computer- based randomization tool and maximally tolerated imbalance procedure with up to $10 \%$ allowable deviation to maintain similar comparison group sizes while limiting predictability of future treatment assignments [41]. Allocation concealment is achieved as the randomization is a fully automated process. However, it is not feasible to blind clinicians or patients to treatment. Due to resource limitations that allowed for only one full-time STAR navigator, the total daily number of patients randomized is constrained to include up to six patients each weekday (from the daily list of eligible patients, sorted by time of presentation). The randomization constraint is reevaluated on a biweekly basis and adjusted as needed to match the STAR navigator's capacity.

\section{Data collection}

Navigators document completion of STAR workflow processes in the patient's EHR through the care management electronic documentation form, and then data are exported into a secure, research database (REDCap) [42]. All clinical 
and outcomes data are collected directly from the AH EHR system and Enterprise Data Warehouse (EDW). Data for study population description are presented in Table 2 . Data are collected on a near real-time basis and include physiologic measurements (e.g., mean arterial pressure), laboratory values (complete blood count, basic/comprehensive metabolic panel, lactate), basic sociodemographic characteristics (e.g., age, gender, race, marital status, insurance status), past medical history (e.g., comorbidities, prior healthcare use, medication history), hospital procedures (e.g., mechanical ventilation), and organizational variables (e.g., hospital).

\section{Study outcomes}

The primary outcome is a composite, dichotomous endpoint of all-cause mortality or unplanned hospital readmission assessed 30 days post index hospital discharge (Table 3). This combined outcome is ideally suited to our pragmatic study design because the elements are uniformly captured from data contained in the AH EDW, minimizing non-differential assessment, outcome misclassification, and missing data. Additionally, mortality and hospital readmission are widely regarded as patient-centered outcomes, and rates for both adverse outcomes remain high after sepsis hospitalization [43-45]. Finally, readmission rates have recently declined secondary to focused initiatives [46]. However, some data suggest increased mortality during the same interval [47], indicating the importance of measuring mortality and readmission rates in combination. Mortality is defined as any date of death documented in the AH EDW from index hospital presentation to within 30 days of index hospital discharge, including events from national death record data fed monthly into the EDW [48]. Readmission is defined as any unplanned inpatient or observation encounter to any of $47 \mathrm{AH}$ hospitals within the 30 days following index hospital discharge. Both inpatient and observation status hospitalizations count toward the readmission outcome, because either status represents an adverse event important to patients and healthcare systems. This information is captured from encounter data in the AH EDW and has been previously extracted by the study team.

The following secondary outcomes are assessed at 30 and 90 days after hospital discharge: all-cause mortality; all-cause, unplanned hospital readmission; cause-specific hospital readmissions with primary diagnoses (based on International Classification of Diseases, 10th revision diagnosis codes) related to sepsis or common infection (i.e., sepsis (A40-41, R65.2021), pneumonia (J13-18), urinary tract infection (N30, N34, N39.0), skin and soft tissue infection (L00-08)), chronic lung disease (J40-47), heart failure (I50), and acute renal failure (N17); ED visits; acute care costs for services received at $\mathrm{ED}$, inpatient, or observation encounters to any AH facility; total healthcare costs for inpatient and outpatient services received at any $\mathrm{AH}$ or outside system hospital or provider clinic (only in the subgroup of patients enrolled in a Medicare Shared Savings Plan with complete claims data tracked in $\mathrm{AH}$ EDW); and acute care-free days alive, defined as the sum of days alive without inpatient, observation, or ED encounters (rounded to a full day for any day with acute care utilization) during the interval after discharge. First, the total potential follow-up time is calculated as the number of days from index discharge to the earliest date of death or 30 (or 90) days post discharge (patients who die during their index hospitalization have 0 days alive). Each potential follow-up day is categorized as either an acute care day or an acute care-free day, based on any inpatient, observation, or ED encounter on that day. Total acute care-free days alive are calculated as the total potential follow-up time minus the number of acute care days during the 30 (or 90) days after index hospital discharge.

To provide additional context to understanding STAR implementation, important process measures are tracked in both groups, including: functional assessment or physical therapy consult $[49,50]$; mental health assessment by PHQ-2 or PHQ-9 [51]; referrals to physical therapy or outpatient rehabilitation, speech therapy, and behavioral health [52-55]; early outpatient follow-up (i.e., completed outpatient primary care follow-up (or attendance at an AH Transition Services clinic) within 7 days of discharge) [56-60]; and documented medication reconciliation in the EHR during the 30 days post discharge $[61,62]$. Because sepsis may occur in the setting of long-standing illness and declining health [63-65], we also measure the quality of end-of-life care, including place of death (i.e., hospital or other location) and the proportion of patients who received a palliative care consult, completed care preferences documentation, and were discharged to a hospice.

\section{Statistical analysis}

Primary analyses will follow an intent-to-treat approach such that patients will be analyzed based on the group to which they were initially randomized after exclusion of patients with infection ruled out during their hospitalization. We will assess the balance in the distributions of baseline covariates for patient factors (e.g., age, comorbidities), acuity (e.g., organ dysfunction, mechanical ventilation), length of stay, and discharge disposition (e.g., SNF, rehabilitation, home) between study groups. Comparisons of the two groups will be made using univariate analyses such as the $t$ test and chi-square test. 
Table 2 IMPACTS study patient characteristics

\begin{tabular}{|c|c|c|}
\hline Characteristic & Usual care $(n=)$ & STAR program $(n=)$ \\
\hline \multicolumn{3}{|l|}{ Age at admission (years) } \\
\hline Median (IQR) & - & - \\
\hline$>65$ years & - & - \\
\hline \multicolumn{3}{|l|}{ Gender } \\
\hline Male & - & - \\
\hline Female & - & - \\
\hline \multicolumn{3}{|l|}{ Race } \\
\hline White & - & - \\
\hline Black & - & - \\
\hline Other & - & - \\
\hline \multicolumn{3}{|l|}{ Marital status } \\
\hline Married & - & - \\
\hline Separated or divorced & - & - \\
\hline Single & - & - \\
\hline Widowed & - & - \\
\hline \multicolumn{3}{|l|}{ Insurance } \\
\hline Medicare & - & - \\
\hline Medicaid & - & - \\
\hline Private & - & - \\
\hline Self pay/other & - & - \\
\hline \multicolumn{3}{|l|}{ Comorbid conditions } \\
\hline Chronic lung disease & - & - \\
\hline Chronic renal disease & - & - \\
\hline Diabetes & - & - \\
\hline Heart failure & - & - \\
\hline Malignancy & - & - \\
\hline Myocardial infarction & - & - \\
\hline Peripheral vascular disease & - & - \\
\hline Charlson Comorbidity Index, median (IQR) & - & - \\
\hline Number of hospital admissions $<6$ months, median (IQR) & - & - \\
\hline \multicolumn{3}{|l|}{ Index hospitalization organ dysfunction measures } \\
\hline Mean arterial pressure (mmHg), median (IQR) & - & - \\
\hline Mean arterial pressure $<70 \mathrm{mmHg}, n(\%)$ & - & - \\
\hline Creatinine (mg/dl), median (IQR) & - & - \\
\hline Creatinine > $2.0 \mathrm{mg} / \mathrm{dl}, n$ (\%) & - & - \\
\hline Bilirubin (mg/dl), median (IQR) & - & - \\
\hline Bilirubin $>2.0 \mathrm{mg} / \mathrm{dl}, n(\%)$ & - & - \\
\hline Platelets (cells/ $\mu \mathrm{l})$, median (IQR) & - & - \\
\hline Platelets < 100 cells/ $\mu \mathrm{l}, n$ (\%) & - & - \\
\hline Lactate (mmol/L), median (IQR) & - & - \\
\hline Lactate $\geq 2.0 \mathrm{mmol} / \mathrm{L}, n(\%)$ & - & - \\
\hline Mechanical ventilation during index hospitalization & - & - \\
\hline Vasopressor receipt during index hospitalization & - & - \\
\hline
\end{tabular}


Table 3 IMPACTS primary and secondary outcomes

\begin{tabular}{|c|c|c|}
\hline Clinical and cost outcomes & Usual care $(n=)$ & STAR program $(n=)$ \\
\hline \multicolumn{3}{|l|}{ Primary outcome } \\
\hline 30-day all-cause mortality or hospital readmission & - & - \\
\hline \multicolumn{3}{|l|}{ Secondary outcomes } \\
\hline 30-day all-cause mortality & - & - \\
\hline 30-day hospital readmission & - & - \\
\hline 30-day sepsis/infection-related hospital readmission & - & - \\
\hline 30-day chronic lung disease-related hospital readmission & - & - \\
\hline 30-day heart failure-related hospital readmission & - & - \\
\hline 30-day acute renal failure-related hospital readmission & - & - \\
\hline 30-day emergency department visits & - & - \\
\hline 30-day acute care-free days alive & - & - \\
\hline 30-day acute care costs & - & - \\
\hline 30-day total healthcare costs ${ }^{a}$ & - & - \\
\hline 90-day all-cause mortality & - & - \\
\hline 90-day hospital readmission & - & - \\
\hline 90-day sepsis/infection-related hospital readmission & - & - \\
\hline 90-day chronic lung disease-related hospital readmission & - & - \\
\hline 90-day heart failure-related hospital readmission & - & - \\
\hline 90-day acute renal failure-related hospital readmission & - & - \\
\hline 90-day emergency department visits & - & - \\
\hline 90-day acute care-free days alive & - & - \\
\hline 90-day acute care costs & - & - \\
\hline 90-day total healthcare costs ${ }^{\mathrm{a}}$ & - & - \\
\hline
\end{tabular}

IMPACTS Improving Morbidity during Post-Acute Care Transitions for Sepsis, STAR Sepsis Transition and Recovery

${ }^{a}$ Only analyzed among Medicare-insured subgroup

The primary composite outcome, 30-day readmission and mortality, will be compared between the two arms using logistic regression. We will present the effects of the STAR program on the incidence of the composite readmission and mortality outcome as odds ratios and $95 \%$ confidence intervals. In addition to the primary intent-to-treat analysis, and since there is significant overlap between general AH Transition Services and the STAR program services integrated within AH Transition Services, we will conduct a modified intent-to-treat analysis excluding usual care patients who attended the $\mathrm{AH}$ Transition Services clinic during the 30 days after hospital discharge. Based on historical data, we anticipate an approximately $10 \%$ referral rate to AH Transition Services in the usual care group. Finally, we will complete a per-protocol analysis to compare patients in the STAR intervention arm who are eligible at hospital discharge and complete the 30-day STAR program to patients who are eligible at hospital discharge and receive usual care.

Secondary acute care and cost outcomes and process measures will be evaluated using the same approach. We will test different distribution parameters to determine the optimal distribution family for each model and outcome variable (e.g., gamma distribution for costs, Poisson distribution for acute care-free days). Any substantial changes to the study processes will be documented, discussed with investigators at monthly meetings, and incorporated into analyses of study outcomes. All hypothesis tests will be two sided and data will be analyzed using SAS Enterprise Guide v7.1 (Cary, NC, USA).

\section{Subgroups}

In addition to the overall study population, primary and secondary outcomes will be compared between the usual care and STAR intervention arms within several clinically relevant subgroups, including: chronic comorbidity burden (i.e., Charlson Comorbidity Index $\geq 5$ or $<$ 5); acute severity of index hospitalization (i.e., septic shock or no shock, defined by fluid-resistant hypotension requiring vasopressors and hyperlactatemia $(>2 \mathrm{mmol} / \mathrm{L}))$ [66]; patients who survive the index hospitalization; and Medicare patients over age 65 years (due to the presence of complete claims data on these patients and the additional financial incentives and 
programs aimed at reducing total and post-acute care spend in this population).

\section{Data Safety and Monitoring Board}

Due to the low risk associated with study participation, no interim analyses are planned to evaluate for potential harm related to the intervention and a Data Safety and Monitoring Board is not convened.

\section{Sample size calculation}

This study is designed to detect a $25 \%$ relative reduction in the primary outcome, the composite rate of 30-day readmission and mortality, which is reasonable given prior literature suggesting that between $22 \%$ and $42 \%$ of hospital readmissions after sepsis are preventable, including data from a secondary analysis of the subgroup of sepsis patients in our previous transitions of care trial (relative risk $=0.49,0.24-0.97$ ) [33]. Based on the historical data, the control group is estimated to have a $40 \%$ combined readmission and mortality rate. Group sample sizes of 354 in the STAR group and 354 in the usual care group achieve $80 \%$ power $(\alpha=0.05)$ to detect a $10 \%$ absolute reduction between the group proportions (i.e., $25 \%$ relative reduction). Under the alternative hypothesis, the proportion in the STAR group is assumed to be $30 \%$.

\section{Missing data}

We do not anticipate substantial missing data because all outcomes are routinely collected variables and utilization is broadly captured within our large integrated system. Values for patients who do not have healthcare utilization or mortality records during the study follow-up interval are assumed to be null. While utilization may occur outside $\mathrm{AH}$, this is not expected to be a major limitation because of the $\mathrm{AH}$ market share and accessibility. Specifically, AH operates three large hospitals in Cabarrus and Mecklenburg Counties and more than 40 hospitals in the region overall. Additionally, any utilization occurring outside the system is anticipated to be non-differentially distributed between groups and thus to impact treatment groups equally. Further, internal historical data indicate that nearly $75 \%$ of high-risk patients are Medicare-insured (i.e., Medicare Shared Savings Plan beneficiaries). For these patients, we will have complete healthcare claims within and outside $\mathrm{AH}$ facilities during the study interval, as captured through participation in the local AH-managed Accountable Care Organization. We will conduct subgroup analyses within this Medicare-insured population and will use these data to explore missing data patterns that can be adjusted using pattern-mixture methods in sensitivity analyses.

\section{Discussion}

The IMPACTS trial evaluates a multifaceted, patientcentered transitional care program for sepsis survivors that focuses on addressing both their immediate postdischarge needs as well as the long-term challenges in managing the downstream effects of sepsis. The intervention centers on a sepsis nurse navigator who aims to empower the patient or caregiver to manage the patient's health condition beyond the intervention period. Evidence of an effective intervention and real-world implementation does not currently exist to guide health system decision-making and investments aimed at improving morbidity and mortality in sepsis survivors. Upon completion, this trial will provide comprehensive data on the effectiveness of delivering best-practice postsepsis care through proactive care coordination to improve outcomes for high-risk patients. Results demonstrating better clinical outcomes for patients in the STAR program would provide evidence that structured care coordination integrated into robust transitions programs can be a useful strategy to improve the immense long-term healthcare burden of sepsis, while null findings would suggest that hospital resources may be better directed toward evaluating other post-sepsis care strategies to improve patient outcomes.

We considered several potential study design approaches while planning the IMPACTS trial. Ultimately, we concluded that a pragmatic, patient-level, randomized clinical trial was the most feasible and appropriate evaluation strategy. One central element in our decisionmaking process was our determination that a patientrandomized approach would not be subject to substantial unplanned cross-over that could bias outcome results. Specifically, physicians will not be able to direct usual care patients to the STAR program because this process will be determined through our automated list generation and randomized allocation. The STAR program will not accept physician referrals during the study interval. Additionally, we determined that the pragmatic design would effectively leverage our robust data systems and objective collection of clinical and outcomes data to facilitate a rigorous, real-world evaluation of post-sepsis care.

We intentionally developed broad infection criteria to initially define adults with suspected serious infection or sepsis, with the additional application of our highperforming risk stratification models to objectively narrow the population to those at the highest risk of poor outcomes and with the potential to benefit most from added support. We anticipate that this approach will include a representative sample of patients with different chronic and acute problems. Because of the expected heterogeneity, we have defined a priori several subgroups of interest to further evaluate possible differential 
effects of the STAR program (e.g., patients with high comorbidity burden).

There are some limitations to this study. The results may not be generalizable to all sepsis survivors because study participants are enrolled from a single healthcare system. However, the inclusion of three heterogeneous hospitals within the healthcare system increases the applicability of our findings. Second, we did not protocolize the usual care arm, thus care provided to patients in this group may be variable or change over time. While this may increase noise in determining the true treatment effect, it is consistent with the concept of a pragmatic study design. The STAR program was developed in partnership with a multidisciplinary team of sepsis stakeholders and designed to be implemented and evaluated in a real-world setting. If effective, this program would offer a timely solution for hospitals facing potential financial penalties for higher-than-expected readmission rates and looming alternate payment models such as bundled payments and shared savings programs for Accountable Care Organizations, which creates incentives to deliver care in less intensive settings during the 90 days after hospitalization.

\section{Trial status}

The IMPACTS trial is an ongoing pragmatic randomized controlled trial evaluating clinical outcomes data for adult patients who receive care through the STAR program versus usual care during and after hospitalization for suspected sepsis. The first patient was enrolled on January 28, 2019. Protocol version 1.0 was applied (date December 17, 2018). Recruitment is anticipated to be completed by the end of 2019 .

\section{Supplementary information}

Supplementary information accompanies this paper at https://doi.org/10 1186/s13063-019-3792-7.

Additional file 1. SPIRIT 2013 Checklist: recommended items to address in a clinical trial.

Additional file 2. SPIRIT Schedule of enrollment, interventions, and assessments.

Additional file 3. Pragmatic-Explanatory Continuum Indicator Summary 2 (PRECIS-2) tool describing the assessment of nine domains used to inform pragmatic trial development.

\section{Acknowledgements}

The authors acknowledge the multidisciplinary team that makes the Sepsis Transition and Recovery program possible and collaboration of the following Atrium Health Acute Care Outcomes Research Network Investigators (in alphabetical order): Ryan Brown, MD; Larry Burke, MD; Shih-Hsiung Chou, PhD; Kyle Cunningham, MD; Susan L. Evans, MD; Scott Furney, MD; Michael Gibbs, MD; Alan Heffner, MD; Timothy Hetherington, MS; Daniel Howard, MD; Marc Kowalkowski, PhD; Scott Lindblom, MD; Andrea McCall; Lewis McCurdy, MD; Andrew McWilliams, MD, MPH; Stephanie Murphy, DO; Alfred Papali, MD; Christopher Polk, MD; Whitney Rossman, MS; Michael Runyon, MD; Mark Russo, MD; Melanie Spencer, PhD; Brice Taylor, MD; Stephanie Taylor, MD, MS.

\section{Authors' contributions}

MK conceived of the design of the study, developed the statistical analysis plan, oversaw study execution, and drafted the manuscript. S-HC contributed to the design of the study, led the risk modeling and data analytics approaches, and helped to draft the manuscript. AM contributed to the design of the study, helped design the intervention, and helped to draft the manuscript. CL carried out the transition services intervention and integration with the study design, and helped to draft the manuscript. SM helped design the intervention, carried out the transition services intervention, and helped to draft the manuscript. WR participated in the coordination of the study design and implementation, and helped to draft the manuscript. AP helped with integration of the study design and intervention, and helped to draft the manuscript. AH contributed to the study design, and helped to draft the manuscript. MR contributed to the study design, and helped to draft the manuscript. LB contributed to the study design, and helped to draft the manuscript. MG helped integrate the study design, intervention, and system strategy and helped to draft the manuscript. SPT conceived the design of the study, helped design the intervention, oversaw study execution, and drafted the manuscript. All authors read and approved the final manuscript.

\section{Funding}

This evaluation is funded by an internal grant from the Atrium Health Division of Adult Acute Care. This research did not receive any other specific grant from funding agencies in the public, commercial, or not-for-profit sectors.

Availability of data and materials

Datasets generated during the current study will not be shared.

Ethics approval and consent to participate

This study has been approved by the Atrium Health Institutional Review Board with a waiver of informed consent as this evaluation utilizes elements routinely collected in usual clinical practice and deemed to present minimal risk to study participants.

Consent for publication

Not applicable.

\section{Competing interests}

The authors declare that they have no competing interests.

\section{Author details}

${ }^{1}$ Center for Outcomes Research and Evaluation, Atrium Health, 1540 Garden Terrace, Suite 308, Charlotte, NC 28203, USA. ²Department of Internal Medicine, Atrium Health, Charlotte, NC, USA. ${ }^{3}$ Ambulatory Care Management, Atrium Health, Charlotte, NC, USA. ${ }^{4}$ Transition Services, Department of Internal Medicine, Atrium Health, Charlotte, NC, USA. ${ }^{5}$ Division of Critical Care, Department of Internal Medicine, Atrium Health, Charlotte, NC, USA ${ }^{6}$ Department of Emergency Medicine, Atrium Health, Charlotte, NC, USA. ${ }^{7}$ Division of Hepatology, Department of Internal Medicine, Atrium Health, Charlotte, NC, USA. ${ }^{8}$ Division of Palliative Care, Department of Internal Medicine, Atrium Health, Charlotte, NC, USA.

Received: 19 June 2019 Accepted: 5 October 2019

Published online: 29 November 2019

\section{References}

1. Fleischmann C, Scherag A, Adhikari NK, et al. Assessment of global incidence and mortality of hospital-treated sepsis. Current estimates and limitations. Am J Respir Crit Care Med. 2016;193(3):259-72.

2. Rhodes A, Evans LE, Alhazzani W, et al. Surviving Sepsis Campaign: International Guidelines for Management of Sepsis and Septic Shock: 2016. Intensive Care Med. 2017:43(3):304-77.

3. Kaukonen KM, Bailey M, Suzuki S, Pilcher D, Bellomo R. Mortality related to severe sepsis and septic shock among critically ill patients in Australia and New Zealand, 2000-2012. JAMA. 2014;311(13):1308-16.

4. Iwashyna TJ, Ely EW, Smith DM, Langa KM. Long-term cognitive impairment and functional disability among survivors of severe sepsis. JAMA. 2010; 304(16):1787-94.

5. Shah FA, Pike F, Alvarez $\mathrm{K}$, et al. Bidirectional relationship between cognitive function and pneumonia. Am J Respir Crit Care Med. 2013;188(5):586-92. 
6. Schuler A, Wulf DA, Lu Y, et al. The impact of acute organ dysfunction on long-term survival in sepsis. Crit Care Med. 2018;46(6):843-9.

7. Borges RC, Carvalho CR, Colombo AS, da Silva Borges MP, Soriano FG. Physical activity, muscle strength, and exercise capacity 3 months after severe sepsis and septic shock. Intensive Care Med. 2015;41(8):1433-44.

8. Annane D, Sharshar T. Cognitive decline after sepsis. Lancet Respir Med. 2015;3(1):61-9.

9. Jackson JC, Hopkins RO, Miller RR, Gordon SM, Wheeler AP, Ely EW. Acute respiratory distress syndrome, sepsis, and cognitive decline: a review and case study. South Med J. 2009;102(11):1150-7.

10. Prescott HC, Langa KM, Iwashyna TJ. Readmission diagnoses after hospitalization for severe sepsis and other acute medical conditions. JAMA. 2015;313(10):1055-7.

11. Huang C, Daniels R, Lembo A, et al. Sepsis survivors' satisfaction with support services during and after their hospitalization. Crit Care Med. 2016; 44(12):425

12. Ortego A, Gaieski DF, Fuchs BD, et al. Hospital-based acute care use in survivors of septic shock. Crit Care Med. 2015;43(4):729-37.

13. Winters BD, Eberlein M, Leung J, Needham DM, Pronovost PJ, Sevransky JE. Long-term mortality and quality of life in sepsis: a systematic review. Crit Care Med. 2010;38(5):1276-83.

14. Nesseler N, Defontaine A, Launey Y, Morcet J, Malledant Y, Seguin P. Longterm mortality and quality of life after septic shock: a follow-up observational study. Intensive Care Med. 2013;39(5):881-8.

15. Prescott HC, Osterholzer JJ, Langa KM, Angus DC, Iwashyna TJ. Late mortality after sepsis: propensity matched cohort study. BMJ. 2016;353:i2375

16. Goodwin AJ, Rice DA, Simpson KN, Ford DW. Frequency, cost, and risk factors of readmissions among severe sepsis survivors. Crit Care Med. 2015; 43(4):738-46.

17. Prescott HC, Langa KM, Liu V, Escobar GJ, Iwashyna TJ. Increased 1-year healthcare use in survivors of severe sepsis. Am J Respir Crit Care Med. 2014;190(1):62-9.

18. Liu V, Lei X, Prescott HC, Kipnis P, Iwashyna TJ, Escobar GJ. Hospital readmission and healthcare utilization following sepsis in community settings. J Hosp Med. 2014;9(8):502-7.

19. Jones TK, Fuchs BD, Small DS, et al. Post-acute care use and hospital readmission after sepsis. Ann Am Thorac Soc. 2015;12(6):904-13.

20. Prescott HC, Angus DC. Enhancing recovery from sepsis: a review. JAMA. 2018;319(1):62-75.

21. Taylor S, Figueroa-Sierra M, Shuman T, et al. Post-sepsis care recommendations are associated with improved patient outcomes but adherence is low [abstract]. Crit Care Med. 2019;47(1):636.

22. Brownson RC, Allen P, Duggan K, Stamatakis KA, Erwin PC. Fostering moreeffective public health by identifying administrative evidence-based practices: a review of the literature. Am J Prev Med. 2012;43(3):309-19.

23. Bodenheimer T. Coordinating care-a perilous journey through the health care system. N Engl J Med. 2008;358(10):1064-71.

24. Coleman EA, Berenson RA. Lost in transition: challenges and opportunities for improving the quality of transitional care. Ann Intern Med. 2004;141(7):533-6.

25. Kim CS, Flanders SA. In the clinic. Transitions of care. Ann Intern Med. 2013; 158(5 Pt 1):ITC3-1.

26. Tschudy MM, Raphael JL, Nehal US, et al. Barriers to Care Coordination and Medical Home Implementation. Pediatrics. 2016;138(3):e20153458.

27. Wagner EH. Chronic disease management: what will it take to improve care for chronic illness? Eff Clin Pract. 1998;1(1):2-4.

28. Chan AW, Tetzlaff JM, Altman DG, et al. SPIRIT 2013 statement: defining standard protocol items for clinical trials. Ann Intern Med. 2013;158(3):200-7.

29. Loudon K, Treweek S, Sullivan F, Donnan P, Thorpe KE, Zwarenstein M. The PRECIS-2 tool: designing trials that are fit for purpose. BMJ. 2015;350:h2147.

30. Seymour CW, Liu VX, Iwashyna TJ, et al. Assessment of clinical criteria for sepsis: for the Third International Consensus Definitions for Sepsis and Septic Shock (Sepsis-3). JAMA. 2016;315(8):762-74.

31. Chou S, Taylor S, Kowalkowski M, et al. Performance diminishes when risk models created for proximal outcomes are applied to distal outcomes. Abstract published at Hospital Medicine 2019, March 24-27, National Harbor, Md. Abstract 154. https://www.shmabstracts.com/abstract/performancediminishes-when-risk-models-created-for-proximal-outcomes-are-applied-todistal-outcomes/.

32. McWilliams A, Roberge J, Moore CG, et al. Aiming to Improve Readmissions Through InteGrated Hospital Transitions (AIRTIGHT): study protocol for a randomized controlled trial. Trials. 2016;17(1):603.
33. McWilliams A, Roberge J, Anderson WE, et al. Aiming to Improve Readmissions Through InteGrated Hospital Transitions (AIRTIGHT): a pragmatic randomized controlled trial. J Gen Intern Med. 2019;34(1):58-64.

34. Kroenke K, Spitzer RL, Williams JB. The Patient Health Questionnaire-2: validity of a two-item depression screener. Med Care. 2003;41(11):1284-92.

35. Serafim R, Gomes JA, Salluh J, Povoa P. A comparison of the Quick-SOFA and systemic inflammatory response syndrome criteria for the diagnosis of sepsis and prediction of mortality: a systematic review and meta-analysis. Chest. 2018;153(3):646-55.

36. Fernando SM, Tran A, Taljaard M, et al. Prognostic accuracy of the Quick Sequential Organ Failure Assessment for mortality in patients with suspected infection: a systematic review and meta-analysis. Ann Intern Med. 2018;168(4):266-75

37. Weissman DE, Meier DE. Identifying patients in need of a palliative care assessment in the hospital setting: a consensus report from the Center to Advance Palliative Care. J Palliat Med. 2011;14(1):17-23.

38. Yende S, Linde-Zwirble W, Mayr F, Weissfeld LA, Reis S, Angus DC. Risk of cardiovascular events in survivors of severe sepsis. Am J Respir Crit Care Med. 2014;189(9):1065-74

39. Ou SM, Chu H, Chao PW, et al. Long-term mortality and major adverse cardiovascular events in sepsis survivors. A nationwide population-based study. Am J Respir Crit Care Med. 2016;194(2):209-17.

40. Shen $H N$, Lu CL, Yang HH. Risk of recurrence after surviving severe sepsis: a matched cohort study. Crit Care Med. 2016;44(10):1833-41.

41. Berger WW, Ivanova A, Knoll MD. Minimizing predictability while retaining balance through the use of less restrictive randomization procedures. Stat Med. 2003;22(19):3017-28.

42. Harris PA, Taylor R, Thielke R, Payne J, Gonzalez N, Conde JG. Research electronic data capture (REDCap) — a metadata-driven methodology and workflow process for providing translational research informatics support. J Biomed Inform. 2009;42(2):377-81.

43. Gaudry S, Messika J, Ricard JD, et al. Patient-important outcomes in randomized controlled trials in critically ill patients: a systematic review. Ann Intensive Care. 2017;7(1):28.

44. Liu V, Escobar GJ, Greene JD, et al. Hospital deaths in patients with sepsis from 2 independent cohorts. JAMA. 2014;312(1):90-2.

45. Mayr FB, Talisa VB, Balakumar V, Chang CH, Fine M, Yende S. Proportion and cost of unplanned 30-day readmissions after sepsis compared with other medical conditions. JAMA. 2017;317(5):530-1.

46. Zuckerman RB, Sheingold SH, Epstein AM. The Hospital Readmissions Reduction Program. N Engl J Med. 2016;375(5):494.

47. Gupta A, Allen LA, Bhatt DL, et al. Association of the Hospital Readmissions Reduction Program implementation with readmission and mortality outcomes in heart failure. JAMA Cardiol. 2018;3(1):44-53.

48. Foster SO, Schubauer-Berigan MK, Waters KM. The specificity of the National Death Index and Social Security Administration Death Master File when information on Social Security Number is lacking. Am J Epi. 2000;151(11):S43.

49. Hoyer EH, Needham DM, Atanelov L, Knox B, Friedman M, Brotman DJ. Association of impaired functional status at hospital discharge and subsequent rehospitalization. J Hosp Med. 2014;9(5):277-82.

50. Greysen SR, Stijacic Cenzer I, Auerbach AD, Covinsky KE. Functional impairment and hospital readmission in Medicare seniors. JAMA Intern Med. 2015;175(4):559-65.

51. Pederson JL, Warkentin LM, Majumdar SR, McAlister FA. Depressive symptoms are associated with higher rates of readmission or mortality after medical hospitalization: a systematic review and meta-analysis. J Hosp Med. 2016;11(5):373-80

52. Rogers AT, Bai G, Lavin RA, Anderson GF. Higher hospital spending on occupational therapy Is associated with lower readmission rates. Med Care Res Rev. 2017;74(6):668-86.

53. Freburger JK, Li D, Fraher EP. Community use of physical and occupational therapy after stroke and risk of hospital readmission. Arch Phys Med Rehabil. 2018;99(1):26-34 e25.

54. Bruce ML, Lohman MC, Greenberg RL, Bao Y, Raue PJ. Integrating depression care management into Medicare home health reduces risk of 30- and 60-day hospitalization: the Depression Care for Patients at Home cluster-randomized trial. J Am Geriatr Soc. 2016:64(11):2196-203.

55. Chen J, Novak P, Barath D, Goldman H, Mortensen K. Local health departments' promotion of mental health care and reductions in 30-day allcause readmission rates in Maryland. Med Care. 2018;56(2):153-61. 
56. Jencks SF, Williams MV, Coleman EA. Rehospitalizations among patients in the Medicare fee-for-service program. N Engl J Med. 2009;360(14):1418-28.

57. Hernandez AF, Greiner MA, Fonarow GC, et al. Relationship between early physician follow-up and 30-day readmission among Medicare beneficiaries hospitalized for heart failure. JAMA. 2010;303(17):1716-22.

58. Sharma G, Kuo YF, Freeman JL, Zhang DD, Goodwin JS. Outpatient followup visit and 30-day emergency department visit and readmission in patients hospitalized for chronic obstructive pulmonary disease. Arch Intern Med. 2010;170(18):1664-70.

59. Field TS, Ogarek J, Garber L, Reed G, Gurwitz JH. Association of early postdischarge follow-up by a primary care physician and 30-day rehospitalization among older adults. J Gen Intern Med. 2015;30(5):565-71.

60. Shen E, Koyama SY, Huynh DN, et al. Association of a dedicated posthospital discharge follow-up visit and 30-day readmission risk in a Medicare Advantage population. JAMA Intern Med. 2017:177(1):132-5.

61. Mueller SK, Sponsler KC, Kripalani S, Schnipper JL. Hospital-based medication reconciliation practices: a systematic review. Arch Intern Med. 2012;172(14):1057-69.

62. Christensen M, Lundh A. Medication review in hospitalised patients to reduce morbidity and mortality. Cochrane Database Syst Rev. 2016;2: CD008986.

63. Nasa P, Juneja D, Singh O. Severe sepsis and septic shock in the elderly: an overview. World J Crit Care Med. 2012;1 (1):23-30

64. Rowe TA, McKoy JM. Sepsis in older adults. Infect Dis Clin N Am. 2017;31(4): 731-42.

65. Kadri SS, Rhee C, Strich JR, et al. Estimating ten-year trends in septic shock incidence and mortality in United States academic medical centers using clinical data. Chest. 2017;151(2):278-85.

66. Shankar-Hari M, Phillips GS, Levy ML, et al. Developing a new definition and assessing new clinical criteria for septic shock: for the Third International Consensus Definitions for Sepsis and Septic Shock (Sepsis-3). JAMA. 2016; 315(8):775-87.

\section{Publisher's Note}

Springer Nature remains neutral with regard to jurisdictional claims in published maps and institutional affiliations.

Ready to submit your research? Choose BMC and benefit from:

- fast, convenient online submission

- thorough peer review by experienced researchers in your field

- rapid publication on acceptance

- support for research data, including large and complex data types

- gold Open Access which fosters wider collaboration and increased citations

- maximum visibility for your research: over $100 \mathrm{M}$ website views per year

At $\mathrm{BMC}$, research is always in progress.

Learn more biomedcentral.com/submissions 